\title{
Constructing a Diversified Teaching Evaluation System for Computer's Public Course
}

\author{
Ying Tu \\ School of Mathematics and Computer, Jianghan University, Wuhan , 430056, China \\ tuyinghua@163.com
}

\begin{abstract}
Teaching evaluation could enhance students' motivation and inspire students' interest while helping teachers to adjust and improve their way to teach and finally achieve the goal to improve teaching quality. In the teaching reform of Computer's Public Courses, how to build a diverse and open teaching evaluation system is the focus of attention. This paper introduced the construction of teaching evaluation system for Computer's Public Courses in two aspects of both teaching and learning. Teaching evaluation to teacher is a combination of student evaluation, colleague evaluation, self-evaluation and expert evaluation. Teaching evaluation to student may use e-exam system, examination by presentation or evaluation for works. To make students involved throughout the learning process with enhanced initiative and attention to learn computer course, one of the useful means is to build classroom learning evaluation system.
\end{abstract}

Index Terms-Computer's Public Courses, e-learning, evaluation systems, teaching reforms

\section{Introduction}

Computer's Public Course refers to computer's course offered to students who are not computer science majors. In recent years, to solve the issues in Computer's Public Courses, we have done research into the capability training based Computer's Public Course reform with school's great support. After several years' exploration and practice, our university's Computer's Public Course teaching mode gradually switched from traditional "classroom teaching + multimedia aided teaching" to "computer room teaching + students autonomic learning + open self study"

For computer room teaching, theoretical and experimental classes are combined to take place in multimedia lab. This combination aims at student's integrated problem solving ability. In schedule, theoretical and experimental classes are closely coordinated to make sure the two types of courses can support and enhance of each other.

Generally speaking, Computer's Public Courses share the problem of finishing multiple contents within very limited time. So some students will lose interest gradually when they are not able to catch up with the teaching progress. To tackle this issue, our university opened computer room for students' autonomic learning at out-of-class time. Now students may make use of Local Area Network based computer autonomic learning platform to study theory and do experiments, unlike the historical situation that students can only do hands on experiments in experimental courses. Meanwhile, different level student can also arrange learning time by themselves depending on their own progress, so that their learning efficiency has been greatly improved.

At the same time, Internet based autonomic teaching is added. Learning website has been constructed to enable students to learn a whole course online with aids of syllabus and e-teaching plan. New web based teaching method like BBS also offers a new way for learning related communication. When one student raises questions, both teachers and other students can join discussion to answer. The discussion and communication between teachers and students completed acquiring and deepening of knowledge. By means of online quiz, students' learning status can be reviewed. What's more, students' individual needs can also be satisfied.

To adapt to the changes in Computer's Public Course, we also have done exploration and practice in teaching method, teaching means and teaching evaluation respectively. Among them, teaching evaluation is the last step of teaching. It is the review for teaching efficiency and feedback for teaching process and plays an important role to ensure high teaching quality. In Computer's Public Course reform, we set out from two aspects of both teacher and student to closely combine the two steps of teaching and evaluation to make the process of evaluation go through the whole teaching process.

\section{Teaching evaluation to teacher}

Teaching evaluation is a powerful method to motivate teachers to reflect and improve teaching. It can increase teachers' channels of getting feedback and help teacher to diagnose, analyze as well as make progress and promote teachers to constantly advance in teaching.

To evaluation teachers' teaching scientifically, objectively and accurately, teachers' teaching evaluation will be a combination of students' evaluation, colleague evaluation, self -evaluation and expert evaluation.

\subsection{Students evaluation}

In the e-learning mode of "computer room teaching + students autonomic learning + open self-study", students enjoy more time and measure to keep in touch with teachers, so as to have a better understanding about every teacher's ability and attitude to teach. So when students evaluate teachers in aspects of using different way to teach, motivating students and

\footnotetext{
* Sponsored by Teaching Research Project from Hubei Education Department (No. 2011251) and Hubei Provincial Education Planing Office(No. 2011B414)
} 
heuristic teaching, the outcome will be relatively accurate and fair.

\subsection{Colleague evaluation}

In every semester, teaching and research section will organize teachers to attend each other's course. Since teachers share a similar professional knowledge background, they are familiar with courses' content, focus and difficulty, profession evaluation cares more about teacher's explanation accuracy on basic concept, basic theory and basic means, level of mastery of course's focus and difficulty as well as skill when teaching in classes.

\subsection{Self-evaluation}

Every semester each teacher will fill in a self-evaluation chart. In this chart, teachers will evaluate themselves regarding their acknowledgement, capability and attitude in teaching according to certain evaluation principles. Timely self evaluation can help teachers to reflect their own disadvantages and finally find out the direction to continue paying effort to.

\subsection{Expert evaluation}

It's reasonable to hire a professional expert to make authoritative evaluation. As experts possess higher academic skills, they are capable to make scientific, accurate and proper evaluation to motivate teachers to continuously improve teaching skills.

\section{Teaching evaluation to student}

Reasonable and timely feedback and evaluation play an indispensable part in maintaining students' motivation and initiative and ensuring high learning quality. Due to the learning evaluation's directing effect, the reasonability of means of evaluation instantly influences teaching quality and building of style of study. Besides final exam grade, student's hands on ability, major assignment result, final outcome of projects and usual performance should be taken into account in overall evaluation. We should base on students' performance and achievement during computer practical operation process or application when solving problems to evaluation students' practical operating capability or informational literacy of other aspects

\subsection{Construction of exam system.}

Since the year 1997, our university has developed Computer's Public Course e-exam system for non-computer majors. After years of construction, this system now covers courses: Fundamentals of Computer, Visual Basic Programming, C Programming, Visual FoxPro Programming. Each course has its own independent test item bank. Test item banks are designed according to syllabus. Test item property includes the chapters involved, knowledge point, type of test item and its difficulty. Test item types are divided into multiple choice questions, fill-in, alternative answer question, Office operating, program analysis, correction and programming. When forming examination paper, according to different difficulty or exam objective required, multiple unduplicated examination paper can be formed. After exams, the examination paper can be automatically graded to increase objectivity and scientificalness and realize separating teaching and examining.

To guarantee test items' timeliness, course coordinator need to organize involved teachers to update test items in the test item banks once in a while. After each major amending, new test items must first go through teaching coordinator and course coordinator's verification and then teachers in the team are organized to try the new items by themselves to make sure the examination has a moderate difficulty and high cover rate of knowledge points.

\subsection{Examination by presentation.}

Examination by presentation is only tested in Visual Basic Course in two classes on 125 students. Since examination by presentation is unfamiliar and irregular way to student, teacher introduced it to students and verified with them. As majority of students accepted, the teacher applied to use examination by presentation and got approved. After that, the examination was finished in three stages.

First stage is preparation for the examination. This stage aims to give students a clear requirement of the exam and write a program to reflect own skill. The exam requirement is: originated ideas are encouraged with bonus. Imitating allowed while the source is well understood by the student and some improvement has been achieved in the student's OWN programming as there are enormous resources online including a lot of useful and interesting Visual Basic programs to learn from and refer to. Plagiarism strictly prohibited and result set to 0 once the program is confirmed to be plagiarized.

On students knowing the form of exam is going to change, the study environment can be felt to change respectively. Autonomic studying students increased apparently and questions from students also increased while range our question also started to cover more than taught section. Students are also preparing their own works while the course is in progress.

Second stage is preparation for the presentation. In this stage teachers mainly offer guidance for students to complete works and prepare for presentation. When students are preparing exam works, teachers will act as a supporter: discuss subject of the final exam presentation; solving problems students encountered during programming and following up about progress with students with relatively weaker academic level. Every student's work needs to hand over to teacher for final inspection one week before the presentation.

Third stage is presentation. Every student needs to present own work to introduce its main function or unique selling point and then answer questions raised by teachers or classmates.

Due to the limited exam time, after several students' volunteering to show everybody the flow of presentation, other students' presentation sequences are decided by a random drawing program. That program is written by a student and changed normal student number sequence and gives everybody 
suspense about next one to present. With all students' participation, the whole presentation examination is highly in order. All kinds of works have been displayed and knowledge points involved are much beyond syllabus requirement.

In this test, students have a high level of participation and initiative. They have earned more than better professional knowledge. What's more, they also practiced express ability, communication ability and organization ability.The final achievement is great.

\subsection{Method of evaluation for works}

For Flash, Photoshop courses that are not suitable for examination paper, the form of examination is a work designed and made by students' independently. The making requirement and respective grading standard is included in examination instruction. Students' work must include various knowledge points required in making requirement. At the same time, the highly detailed score chart makes the students aware of which kind of skill needs to be present in the work. Eventually, teacher will graded according to the integrated usage condition of different knowledge points.

For instance, Flash course requires student to make an ealbum with following standard:

Album document needs to be $800 * 600$ pixels

Album content needs to include more than 5 pictures of Jiang Han University with a total animation length of more than 1 minute.

Album needs to include head leader, photos and tail leader. Head leader must include class and grade, student number and name. Photos should attach dynamic character introduction or other dynamic decoration.

Album must include animation complement, guide line, shape tweening, and mask, these four kinds of animation skills.

Album is cooperated with suitable background music and sound effect.

Buttons are used properly to control the animation playing process.

After students submitted fla source file, teacher will grade according to different items including album content, length, animation complement, guide line, shape tweening, and mask, usage of element, background music and sound effect, movie control as well as overall effect and originality and finally students get respective exam grade.

\subsection{Classroom learning evaluation system}

Some students don't work hard in usual and get used to make preparation at last moment to depend on general revision. A minority even rely on taking chance to cheat in final exam. To change this situation, one of the useful means is to build classroom learning evaluation system to objectively reflect student's daily involvement and reflect in students' usual performance grade to strengthen students' motivation and initiative to participate in course study.

In default, usual performance grading accounts for $30 \%$ of total weight, decided by students' attendance, usual homework, experiment reports, major assignments and course participation.
Students' attendance makes use of e-roll call system, and then use excel to import data and analyze data with respective macro

Usual homework and experiment reports are submitted to homework system on computer autonomic study platform. After marked by teacher, the score is saved into database and form to another source of usual performance in the end of semester.

After one knowledge unit explanation is finished, teacher needs to give in class exercise to help students to consolidate their comprehension to new knowledge through training. Sometimes, one or two students are chosen to present or explain their exercise result. Meanwhile, teacher should praise their corrective or unique way to solve problem, like giving bonus to usual performance grade to motivate students. For common mistakes exposed in solving problems, teacher should emphasize them. By means of this classroom evaluation system, students are encouraged to pay more attention to lecture and initiatively think about in-class exercise, and finally make classroom teaching more effective.

Sometimes major assignments are used to evaluate usual performance. In Fundamentals of Computers, Powerpoint is not listed in range of skill point examination. Major assignment requires students to make PPT by themselves. By operations like importing and inserting text, downloading and inserting pictures, recording and input music as well as choosing template, students are assisted to become familiar with PowerPoint software application and skills. After major assignment, some teachers will display some of works from the same class. Good works made by familiar classmates will harvest a lot of appreciation and further motivate students to study. Among them, excellent works will be submitted to outstanding course website under works gallery section.

Sometimes teacher gives special bonus to reward students' classroom response or positively answering questions from other students in BBS.

\section{Conclusion and recommendation}

Teaching is the basic way to achieve the goal of education and finish the educational task. And teaching evaluation is an important step in teaching process. According to the goal of teaching, teaching evaluation could enhance students' motivation and inspire students' interest while helping teachers to adjust and improve their way to teach and finally achieve the goal to improve teaching quality.

In Computer's Public Course teaching reform, we aim to construct a diverse and open teaching evaluation system. Compared with traditional "One exam matters" final exam, this teaching evaluation requires teachers to be more professional and do more work, meanwhile teaching administration difficulty is also increased which needs teaching administration department's reorganization and support. Further exploration and practice is still needed to form a more scientific and practical teaching evaluation system to promote the development of Computer's Public Course teaching reform. 


\section{References}

[1] Mingyun $\mathrm{Gu}$, and Zhongying Shi, National Middle-and-Long-Term Education and Development Program(2010-2020), Beijing Teacher'Normal University Press, 2010

[2] Peng Liang, and Shihua Jiang., "Research on Teaching of Computer Public Class Education of Pedagogical Kind of Colleges and Universities", Computer Education, (2011) 12, pp 37-39, June 2011

[3] Xin Zhang, "The Status Quo of the Teaching of Computer Basic for Noncomputer Majors in Vocational Colleges and Some Suggestions". Journal of Educational Institute of Jilin Province, vol. 28, no 1, pp 127 128, January 2012
[4] Lili Jiang, "The Probe of University Computer Public Course", Computer CD Software and Applications, vol. 14, no. 5, pp 207, March 2011

[5] Zhike Zuo, "Examination Reform and Innovation in Independent College", China Adult Education, 2009(24), pp. 55-56, December, 2009

[6] Songhua Tan, and Xiaoting Huang, "Current Situation of China's Educational Evaluation and Improvement Suggestions" , Journal of The Chinese Society of Education ,(2012)1, pp 8-11, January 2012

[7] Caiyun Yang, and Junhua Wang. "Building Teaching System in the Computer Applications Base Based on Computational Thinking Perspetive", Higher Education Forum, 2012(2), pp 73-75, February 2012

[8] Xiaojun Hu, "Construction of Teachers' Scientific Evaluation of Distance Learning Mechanism", Journal of The Chinese Society of Education, (2011) 8, pp 87-89, August 2011 